\title{
3-D Image Analysis of Multiphase Materials using Laser Scanning Confocal Microscopy
}

\author{
A.M. Elwazri", P. Wanjara ${ }^{* *}$, M. Brochu ${ }^{*}$ and S. Yue \\ *Department of Metals and Materials Engineering, McGill University, 3610 University Street, \\ Montréal, Québec, H3A 2B2, Canada
}
"National Research Council, Institute for Aerospace Research, Aerospace Manufacturing Technology Center, 5145 Decelles Avenue, Montréal, Québec, H3T 2B2, Canada

For the measurement of the characteristics of lamellar structures, such as pearlite $\left(\mathrm{Fe}_{3} \mathrm{C}\right.$ and ferrite) in steel and Widmanstätten alpha-beta in titanium alloys, the application of laser scanning confocal microscopy (LSCM) enables three-dimensional imaging with a resolution capability that allows quantification of the interlamellar spacing and lamellae thickness with statistical confidence. In particular, z-axis (height) or topographic profiling using LSCM permits accurate measurement of the lamellae spacing and thickness due to the possibility for selecting colony regions in the lamellar structure that are perpendicular to the observation plane. Hence, the application of LSCM for materials characterization has the advantage of permitting relatively simple, effective and efficient analytical output as compared to field emission scanning electron microscopy (FE-SEM) and transmission electron microscopy (TEM) techniques. However, although LSCM is an established characterization method in biological sciences, this technique is recent to the materials science field in North America.

In this work, the lamellar structure in a titanium alloy (Ti-6\%Al-4\%V) and a microalloyed hypereutectoid steel $(1.1 \% \mathrm{C}-0.63 \% \mathrm{Mn}-0.23 \% \mathrm{Si}-0.17 \% \mathrm{~V})$ was characterized using LSCM techniques with an Olympus OLS1200 equipped with a blue argon laser (488 nm) and objective specifications of up to $100 \mathrm{x}$ and a $6 \mathrm{x}$ optical zoom $[1,2]$. As the image produced by scanning the $\mathrm{x}-$ and $y$ - axes with a spot laser beam originates from a shallow focus depth, for the relatively thick metallurgical specimens, successive volumes were acquired along the optical z-axis of the microscope. The series of precisely focused optical images of the metallurgical specimens were then overlapped using reconstruction software to obtain a three-dimensional image of the crosssectional view of the microstructure. This extended focus image was then used to obtain height and intensity information for characterization of topographic features of the pearlite lamellae and Widmanstätten alpha-beta structures (Fig. 1a and c). Specifically, the three-dimensional profiling ability enabled the identification of "peaks" and "valleys" in the microstructure, which correspond to cementite and ferrite in the steel or alpha and beta in the Ti-6\%Al-4\%V, as shown in Fig. $1 \mathrm{~b}$ and $\mathrm{d}$.

From the height profiles the lamellar spacing and/or thickness was calculated for both materials processed using different conditions, the results of which are given in Table 1. The ability to resolve such structural constituents is important in the microstructural conditioning of steels and titanium alloys during the manufacturing process because variations in the microstructure that occur on a scale greater than $1 \mu \mathrm{m}$ have been reported to dominate the fracture process and ductility of these material, while variations smaller than $1 \mu \mathrm{m}$ have indicated considerable effects on strength [3]. Hence the possibility of applying LSCM to rapidly and precisely identify changes in the microstructure resulting from different processing conditions, as demonstrated in the present work, 
may prove to be highly prominent for process and quality control in manufacturing of alpha-beta titanium alloys and carbon steels. Nonetheless, for microstructures in these materials with very fine lamellae that have a spacing or thickness below $100 \mathrm{~nm}$, measurement using LSCM is not suitable and the higher resolution ability of FE-SEM or TEM becomes necessary despite the reduced throughput ability of these techniques, which stems from the greater complexity associated with sample preparation and/or equipment operation for obtaining measurements perpendicular to the orientation of the lamellae.

[1] P. Wanjara, M. Brochu, and M. Jahazi, Mater. Charact., 2005, in press.

[2] A. Elwazri, P. Wanjara and S. Yue, Mater. Charact., 2005, in press.

[3] J.C. Williams and E.A. Starke, Deformation, Processing and Structure, American Society for Metals, Metals Park, 1982.

[4] The authors are grateful to Carsen Group Inc., Markham, ON, Canada and Olympus Industrial America Inc., Melville, NY, for having provided access to the OLS 1200 microscope.
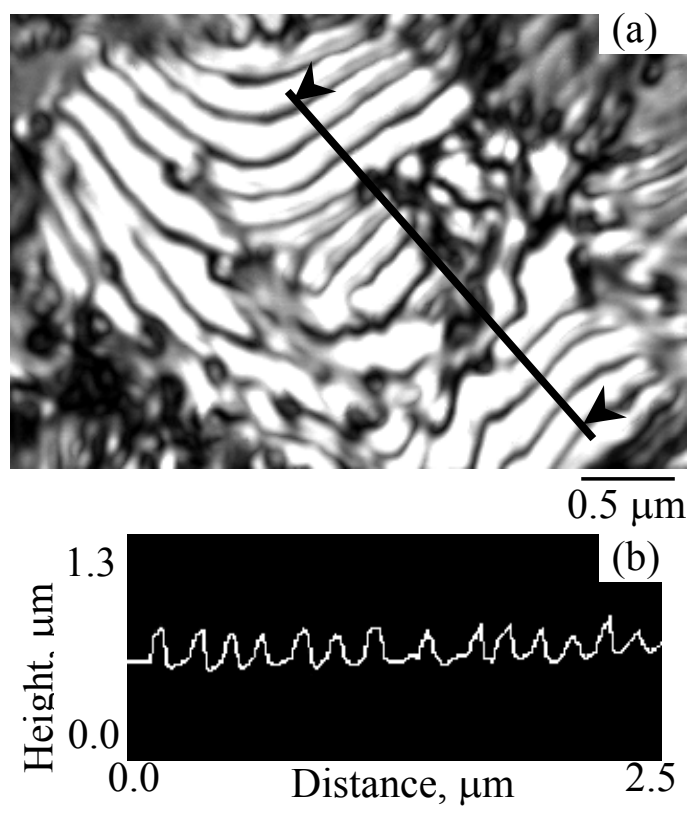

Hypereutectoid steel
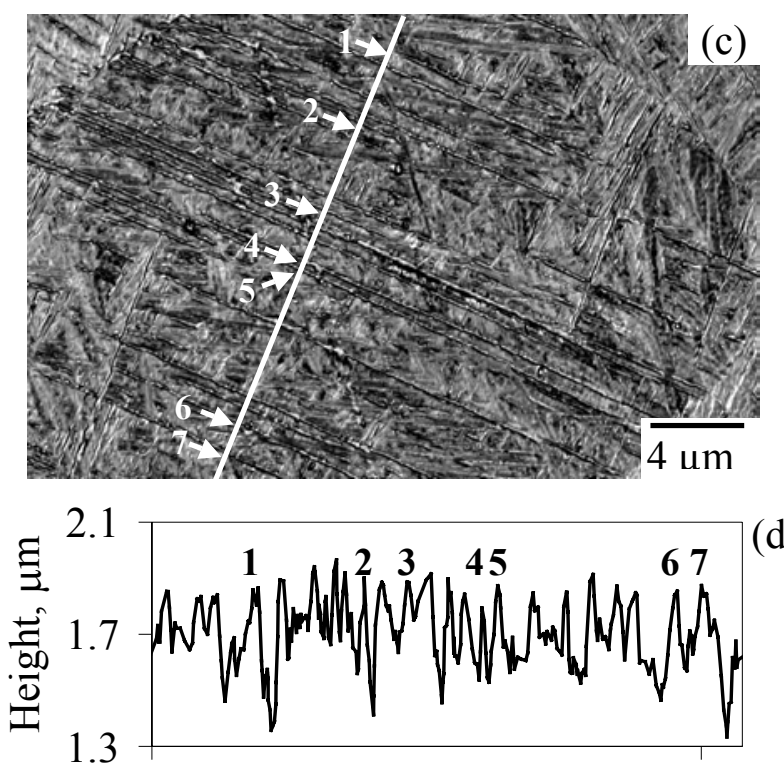

0

.7

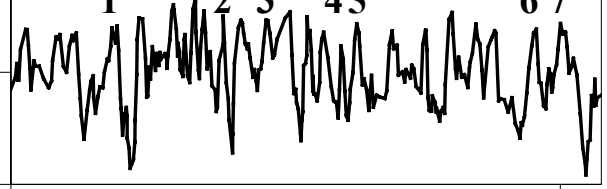

Distance, $\mu \mathrm{m}$ Ti-6\%Al-4\%V

(d)

Fig. 1 LSCM imaging of (a) the pearlite structure with (b) the topographic height analysis across the corresponding line sketched in micrograph and (c) the Widmanstätten structure with (d) the topographic height analysis across the corresponding line sketched in micrograph.

TABLE 1. Lamellar characteristics of pearlitic and Widmanstätten microstructures using LSCM

\begin{tabular}{cccc}
\hline $\begin{array}{c}\text { Processing } \\
\text { Condition }\end{array}$ & $\begin{array}{c}\text { Pearlite structure } \\
\text { Spacing, } \mu \mathrm{m}\end{array}$ & \multicolumn{2}{c}{ Widmanstätten structure } \\
& Spacing, $\mu \mathrm{m}$ & Thickness, $\mu \mathrm{m}$ \\
\hline 1 & $0.15 \pm 0.03$ & $1.83 \pm 0.15$ & $0.93 \pm 0.12$ \\
2 & $0.19 \pm 0.03$ & $2.35 \pm 0.11$ & $1.22 \pm 0.15$ \\
\hline
\end{tabular}

1: Pearlitic steel processed at $550^{\circ} \mathrm{C}$; Widmanstätten Ti-6\%Al-4\%V fast cooled after welding

2: Pearlitic steel processed at $600^{\circ} \mathrm{C}$; Widmanstätten Ti-6\%Al-4\%V slow cooled after welding 